International Journal of Advanced Research in Electrical, Electronics and Instrumentation Engineering

(An ISO 3297: 2007 Certified Organization)

Vol. 4, Issue 3, March 2015

\title{
A Design of Broadband Rectangular Microstrip Antenna with Single Notch Band for Various Wireless Communication Applications
}

\author{
SyedaRafathAra ${ }^{1}$, Dr. S. N. Mulgi ${ }^{2}$ \\ Research Student, Department of Applied Electronics, Gulbarga University, Gulbarga, Karnataka, India ${ }^{1}$ \\ Professor, Department of Applied Electronics, Gulbarga University, Gulbarga, Karnataka, India ${ }^{2}$
}

\begin{abstract}
This paper presents a novel design of partial ground plane rectangular microstrip antenna for dual band operation. The magnitude of each operating band is found to be $95 \%$ and $15.57 \%$. This dual band can be converted into triple bands by placing a stub along the width of the rectangular patch on the right side from the microstripline. The magnitudes of triple bands are found to be $105 \%, 13.57 \%$ and $17.46 \%$. However, the triple bands can be converted into dual bands by placing two stubs simultaneously along the width of the rectangular patch on left and right side of microstripline. The dual bands are merged with single band and antenna gives a highest impedance bandwidth of $137 \%$ with a gain of $6.59 \mathrm{~dB}$ by increasing the length of the stubs from $2 \mathrm{~mm}$ to $4 \mathrm{~mm}$. This operating frequency band of the antennas covers the frequency ranges used for WiMAX, WLAN, Bluetooth, IEEE 802.11a applications. When the length of the stubs is kept at $2 \mathrm{~mm}$ the antenna shows the property of notch band towards the higher side and for $8 \mathrm{~mm}$ towards the lower side of the frequency spectrum. The proposed antennas are simple in their structure and have been realized using low cost glass epoxy substrate material.
\end{abstract}

KEYWORDS: Broadband, Single Notch, Single Stub, Dual Stubs.

\section{I.INTRODUCTION}

Antennas are the most important element of wireless communication systems. For only wireless communication system, the antennas must be of low profile, compact size, light weight, low cost and conformable to the architecture of the connecting devices. Among the various types of antennas the microstrip antennas (MSAs) are the most suitable choice for wireless communication systems [1-3] because these antennas have the advantages of low profile, compactness and easily mountable into wireless devices or enterable with any circuits. In recent years, the developments in wireless communication system technology demands for broadband or ultra wideband antennas. In addition, to avoid the interference, over the allotted wide bandwidth or ultra wide bandwidth of wireless systems, a notch band operated antenna is required between the existing operating bands. A suitable wide band or ultra wide band antenna with notch band operation is in more demand for various communication applications. Many techniques are available in literature to realize broadband MSAs [4-17]. But the design of rectangular microstripline feed with partial ground plane for wide band operation is found to be rare in the literature. The use of stubs along the width of the RMSA for the conversion of dual to triple bands and for triple to single band is also presented. By varying the length of stubs the antenna shows the property of shifting notch bands towards the lower and higher sides of the frequency spectrum. This property of the antenna may find more useful in rejecting the desired frequency in its operating band.

\section{II.ANTENNA GEOMETRY AND DESIGN}

The proposed antennas are designed on modified glass epoxy substrate material of thickness $\mathrm{h}$ is $1.6 \mathrm{~mm}$ and dielectric constant $\epsilon_{\mathrm{r}}$ is 4.2 at $3 \mathrm{GHz}$ using the equations available in the literature. The detailed geometry with parameters of the proposed rectangular microstrip antenna without stub (RMSAWOS) fed by a $50 \Omega$ characteristic impendence microstripline feed is as shown in Fig. 1(a) and a partial grounded substrate is as shown in Fig. 1(b). In Fig. 1 (a) L and 


\section{9 \\ ISSN (Online): $2278-8875$ \\ International Journal of Advanced Research in Electrical, Electronics and Instrumentation Engineering}

ISSN (Print) : $2320-3765$

\section{(An ISO 3297: 2007 Certified Organization)}

\section{Vol. 4, Issue 3, March 2015}

$\mathrm{W}$ are the length and width of the rectangular patch and $\mathrm{L}_{\mathrm{f}}$ and $\mathrm{W}_{\mathrm{f}}$ are the length and width of the microstripline feed. The Ls and Ws are the length and width of the substrate. A $50 \Omega$ microstripline is connected at the centre along the width of the rectangular patch. The $\mathrm{Lg}$ is the height of partial ground plane which is placed on the bottom surface of the substrate as shown in Fig. 1(b).

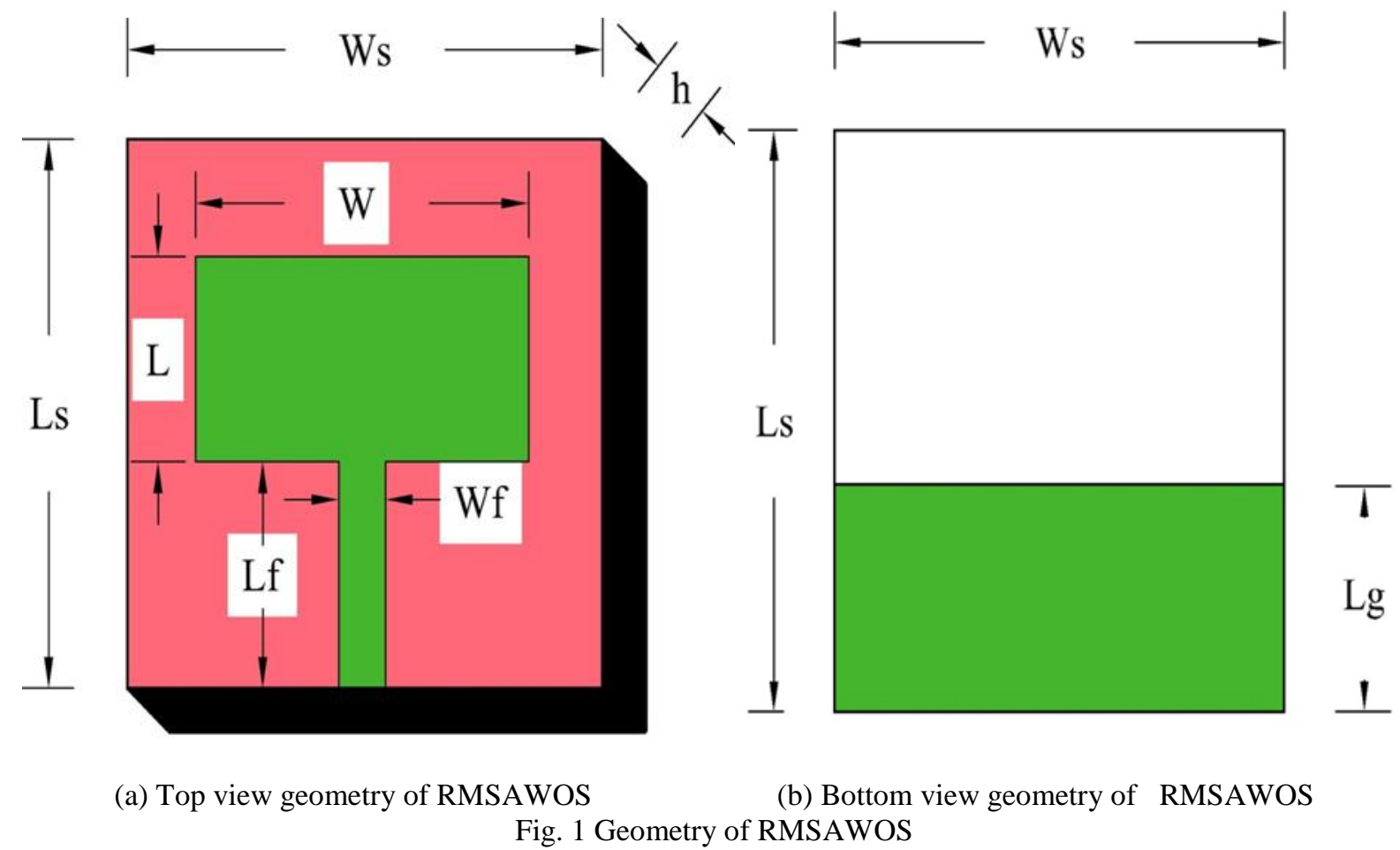

Figure 2(a) and (b) shows the top view geometries of rectangular microstrip antennas with single stub of dimensions L1 and W1 in Fig. 2(a) and L2 and W2 in Fig. 2(b) which are placed along the width of rectangular patch. These antennas are named as RMSAWS1 and RMSAWS2 respectively. The bottom surface of RMSAWS1 and RMSAWS2 remains same as that of Fig. 1(b).

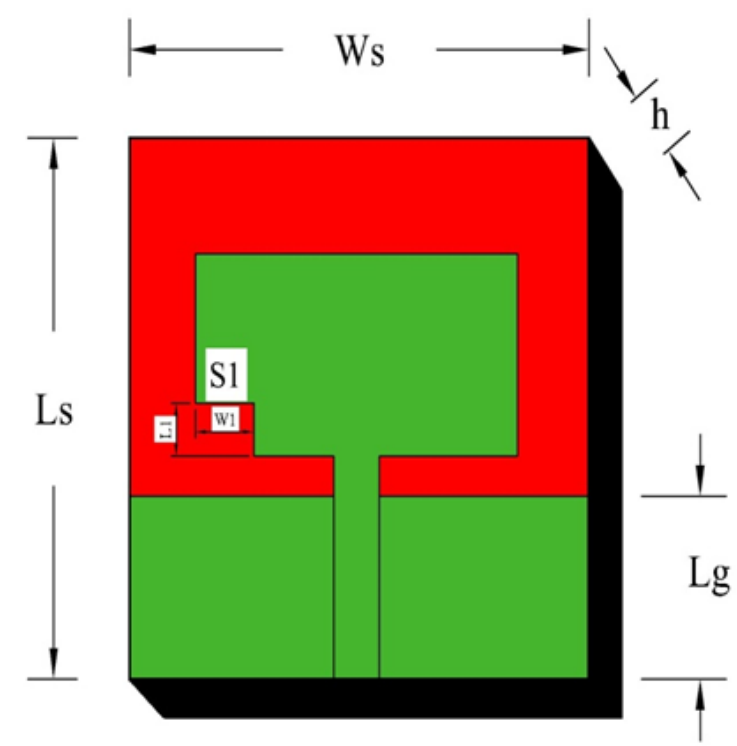

Fig. 2(a) Geometry of RMSAWS1

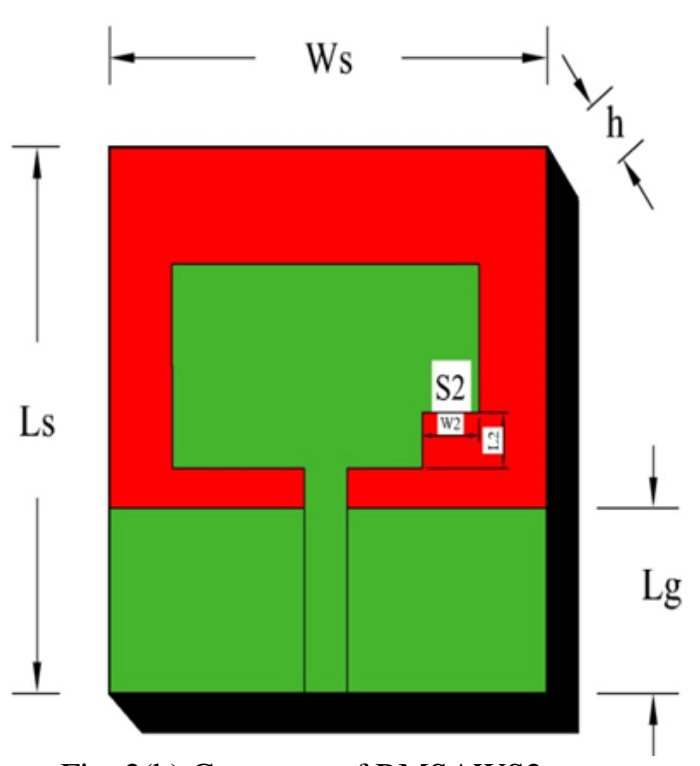

Fig. 2(b) Geometry of RMSAWS2 


\title{
International Journal of Advanced Research in Electrical, Electronics and Instrumentation Engineering
}

\author{
(An ISO 3297: 2007 Certified Organization)
}

\section{Vol. 4, Issue 3, March 2015}

Figure 3 shows the geometry of rectangular microstrip antenna with dual stubs (RMSAWDS). The two stubs S1 and S2 are placed at the same position shown as that of Fig. 2 (a) and Fig. 2(b). The bottom surface of the RMSAWDS remains same as that of Fig. 1 (b). Figure 3(b) shows the side view geometry of RMSAWDS. The details of various antenna parameters are given in Table -1 .

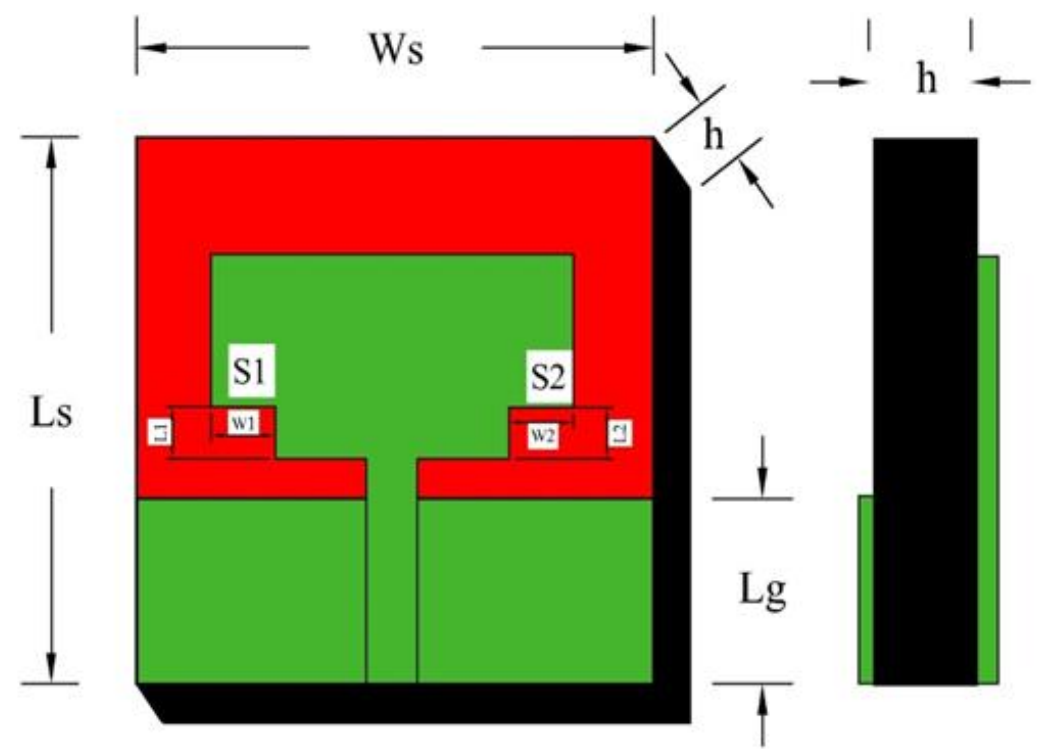

a) Top view of RMSAWDS b) Top view of RMSAWDS

Fig. 3 Geometry of RMSAWDS

Table -1: Designed parameters of proposed antennas

\begin{tabular}{|c|c|c|c|c|c|c|c|c|c|}
\hline Parameters in mm & $\mathrm{L}$ & $\mathrm{W}$ & $\mathrm{L}_{\mathrm{f}}$ & $\mathrm{W}_{\mathrm{f}}$ & $\mathrm{Lg}$ & \multicolumn{2}{|c|}{$\mathrm{S} 1$} & \multicolumn{2}{|c|}{$\mathrm{S} 2$} \\
\hline & & & & & & $\mathrm{L} 1$ & $\mathrm{~W} 1$ & $\mathrm{~L} 2$ & $\mathrm{~W} 2$ \\
\hline RMSAWOS & 24 & 31 & 23.3 & 3.2 & 2.13 & - & - & - & - \\
\hline RMSAWS1 & 24 & 31 & 23.3 & 3.2 & 2.13 & 2 & 5.5 & - & - \\
\hline RMSAWS2 & 24 & 31 & 23.3 & 3.2 & 2.13 & - & - & 2 & 5.5 \\
\hline RMSAWDS & 24 & 31 & 23.3 & 3.2 & 2.13 & 2 & 5.5 & 2 & 5.5 \\
\hline
\end{tabular}

\section{III.RESULTS AND DISCUSSION}

The simulated results of the proposed antennas are carried out by using Ansoft High Frequency Structure simulation (HFSS) software. The variation of return loss curve of RMSAWOS is as shown in Fig. 4. It is seen that, the antenna operates for two band of frequencies B.W.1 and B.W.2. The magnitude of each operating band when return loss is less than $-10 \mathrm{~dB}$ is found to be $95 \%$ for B.W.1(1.42 - $4 \mathrm{GHz})$ and $15.57 \%$ for B.W.2 $(8.41-9.83 \mathrm{GHz})$. The B.W.1 range may be used for WiMax, WLAN, Bluetooth and IEEE 802.11a applications. The B.W.2 range can be used for Synthetic Aperture Radar (SAR) applications. The wide operating frequency range in B.W.1 and resonance band B.W.2 in Fig. 4 are mainly due to the effect of microstripline and partial ground plane of RMSAWOS. 


\section{International Journal of Advanced Research in Electrical, Electronics and Instrumentation Engineering}

(An ISO 3297: 2007 Certified Organization)

\section{Vol. 4, Issue 3, March 2015}

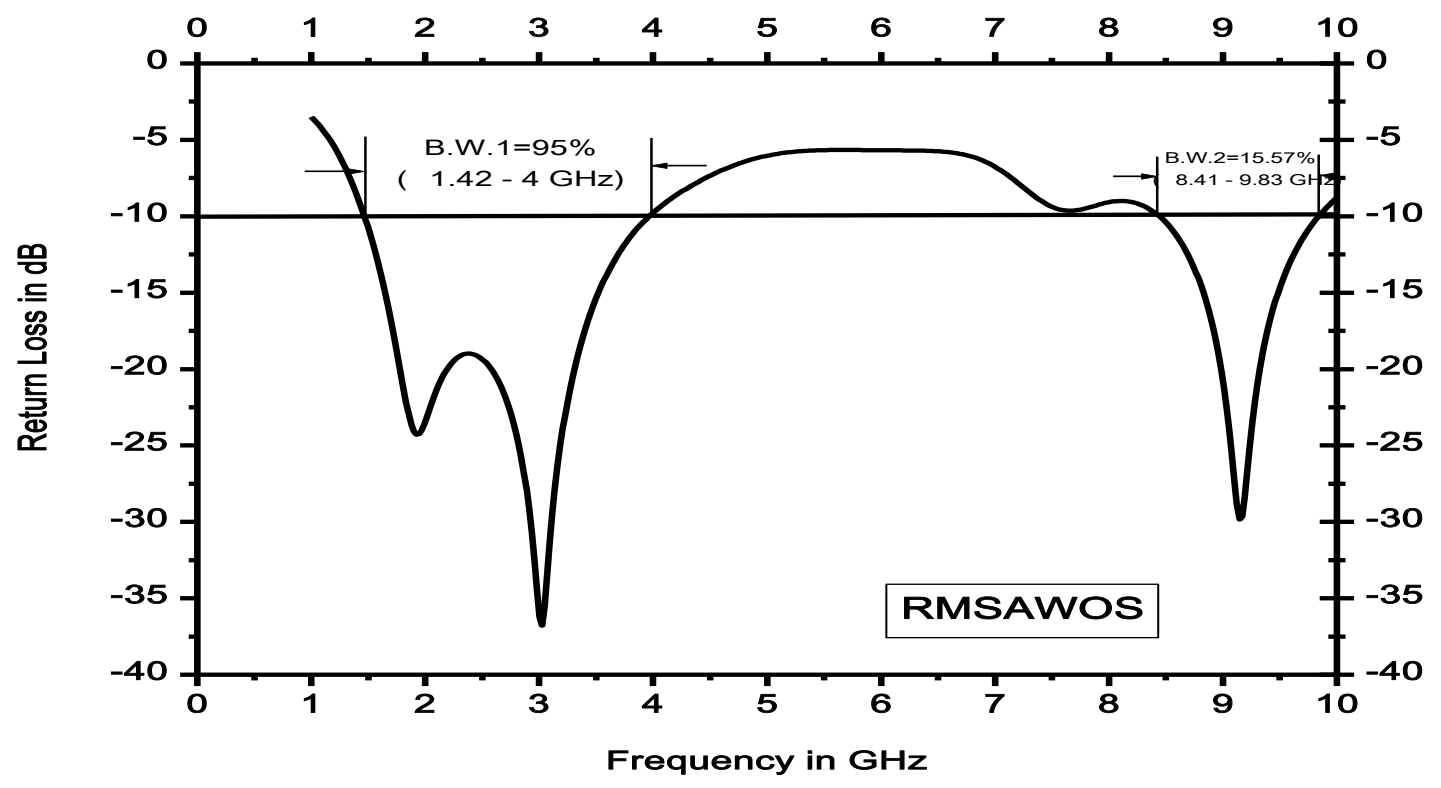

Fig. 4 Variation of return loss versus frequency curve of RMSAWOS

Figure 5 shows the variation of return loss versus frequency curve of RMSAWS1. In this case the stub S1 is placed left side from the microstripline. The bandwidth B.W.1 of Fig. 5 is $6.25 \%$ more than the B.W.1 of Fig. 4 and resonance band B.W.2 of Fig. 5 decreases $9.7 \%$ than the resonance band B.W.2 of Fig. 4. The enhancement of bandwidth B.W.1 in Fig. 5 when compared to B.W.1 of Fig. 4 is due to the effect of stub placed along the width of RMSAWOS. This shows that the use of stub is effective in enhancing the bandwidth of dualband operation of an antenna.

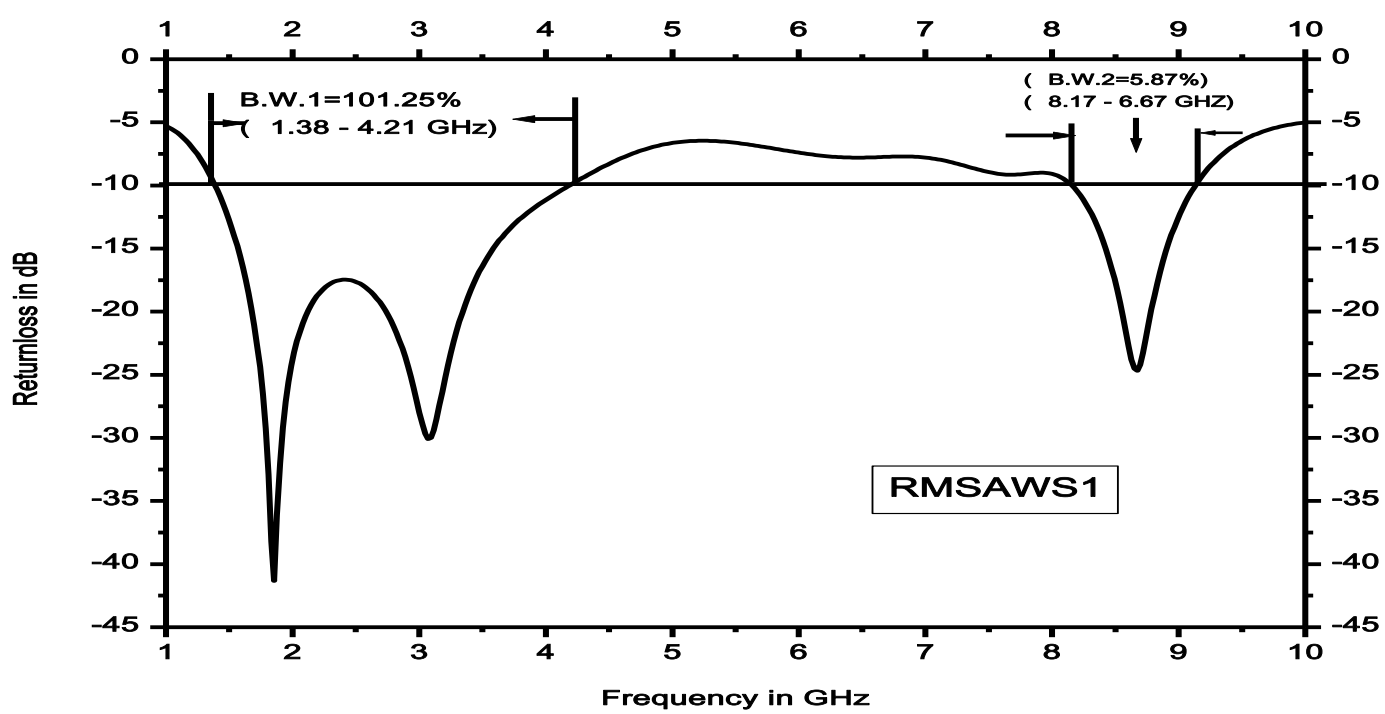

Fig. 5 Variation of return loss versus frequency of RMSAWS1

Figure 6 shows the variation of return loss versus frequency of RMSAWS2. From this figure it is clear that, when stub is placed along the width at the right from the microstripline as shown in Fig. 2 (b) the antenna operates for triple band 


\title{
International Journal of Advanced Research in Electrical, Electronics and Instrumentation Engineering
}

\author{
(An ISO 3297: 2007 Certified Organization)
}

\section{Vol. 4, Issue 3, March 2015}

of frequencies B.W.1, B.W.2 and B.W.3. The magnitude of each operating band is found to be $105 \%(1.42-4.57$ $\mathrm{GHz}), 13.57 \%(7.21-8.26 \mathrm{GHz})$ and $17.46 \%(8.26-9.84 \mathrm{G} \mathrm{Hz})$ respectively.

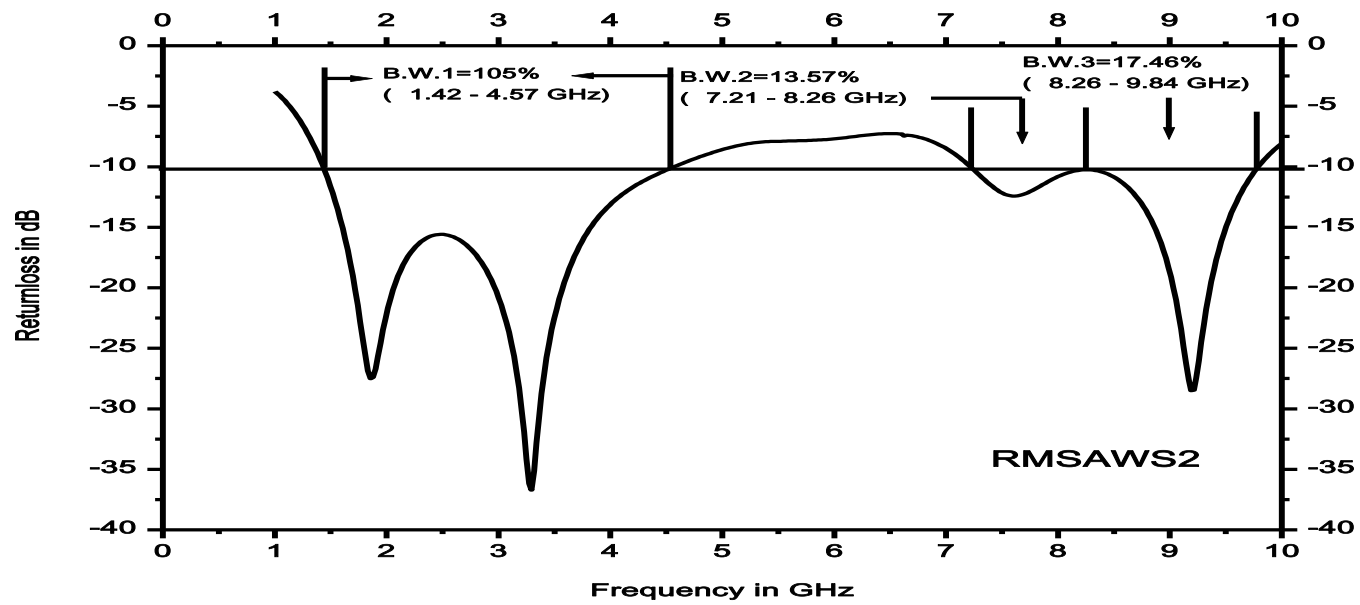

Fig. 6 Variation of return loss versus frequency of RMSAWS2

When two stubs S1 and S2 shown in Fig. 2(a) and Fig. 2(b) are placed simultaneously along the width of the rectangular patch i.e. RMSAWDS with $\mathrm{L}=2 \mathrm{~mm}$ of each stub, the antenna resonates for dual band of frequencies B.W.1 and B.W.2 as shown in Fig. 7. The magnitude of each operating band B.W.1 and B.W.2 are $110 \%(1.34-4.6 \mathrm{GHz})$ and $29.55 \%$ (7.00 - $9.43 \mathrm{GHz})$ respectively. The magnitude of these operating bands B.W.1 and B.W.2 are found to be $15 \%$ and $13.98 \%$ larger than the B.W.1 and B.W.2 of Fig. 4 respectively. Hence, placing of two stubs simultaneously along the width of rectangular patch is effective in enhancing the operating band of dual band operation of RMSAWOS. The use of two stubs which each of area $.11 \mathrm{~cm}\left(.2 \times .55=.11 \mathrm{~cm}^{2}\right)$ also reduces the actual size of rectangular patch by $2.95 \%$ when compared to the size of rectangular patch shown is Fig. 1. Further it is seen in Fig. 7 that the notch band appears from 4.58 to $7.24 \mathrm{GHz}$.

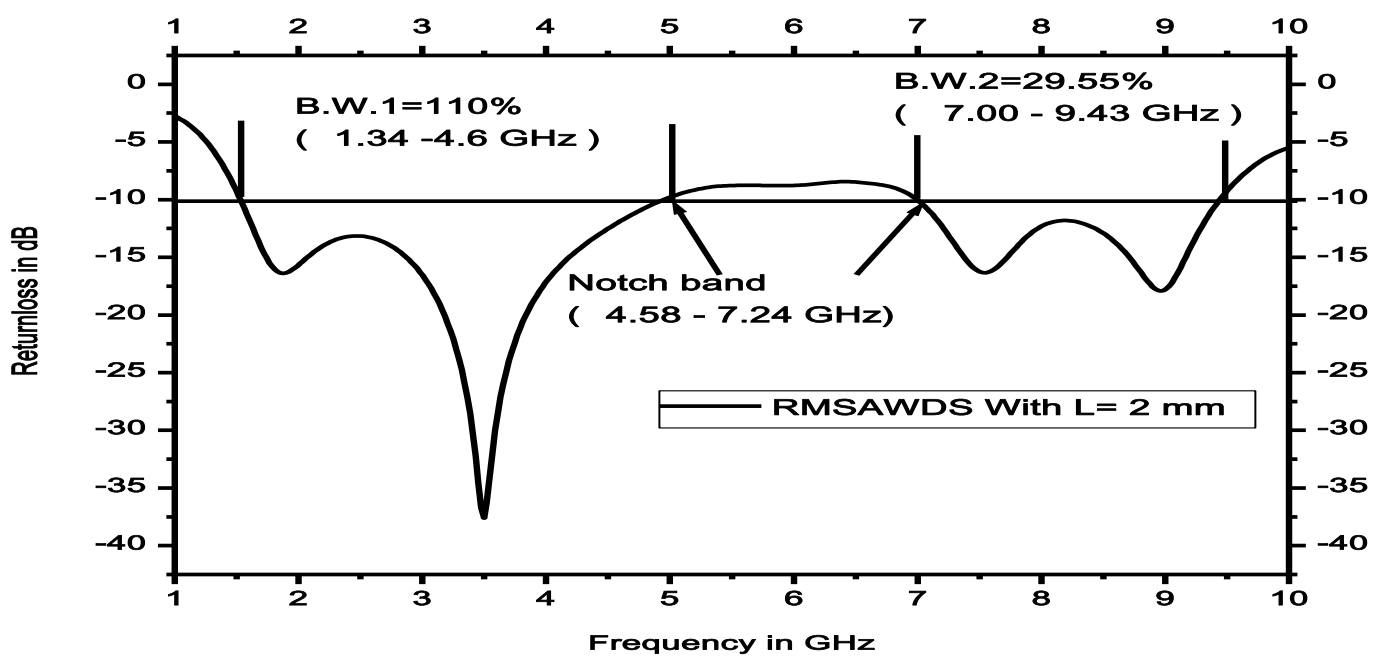

Fig. 7 Variation of return loss versus frequency of RMSAWDS when $\mathrm{L}=2 \mathrm{~mm}$

When length of the stubs shown in Fig. 3(b) is kept at 4mm the, RMSAWDS resonates for single band. The two operating bands shown in Fig. 7 are merged into a single band and antenna gives a highest impedance bandwidth of 


\title{
International Journal of Advanced Research in Electrical, Electronics and Instrumentation Engineering
}

\author{
(An ISO 3297: 2007 Certified Organization)
}

\section{Vol. 4, Issue 3, March 2015}

$137 \%(1.45-7.81 \mathrm{GHz})$ as shown in Fig.8. This range of frequencies covers almost all microwave communication applications. The peak gain of this antenna in this operating band is found to be $6.59 \mathrm{~dB}$.

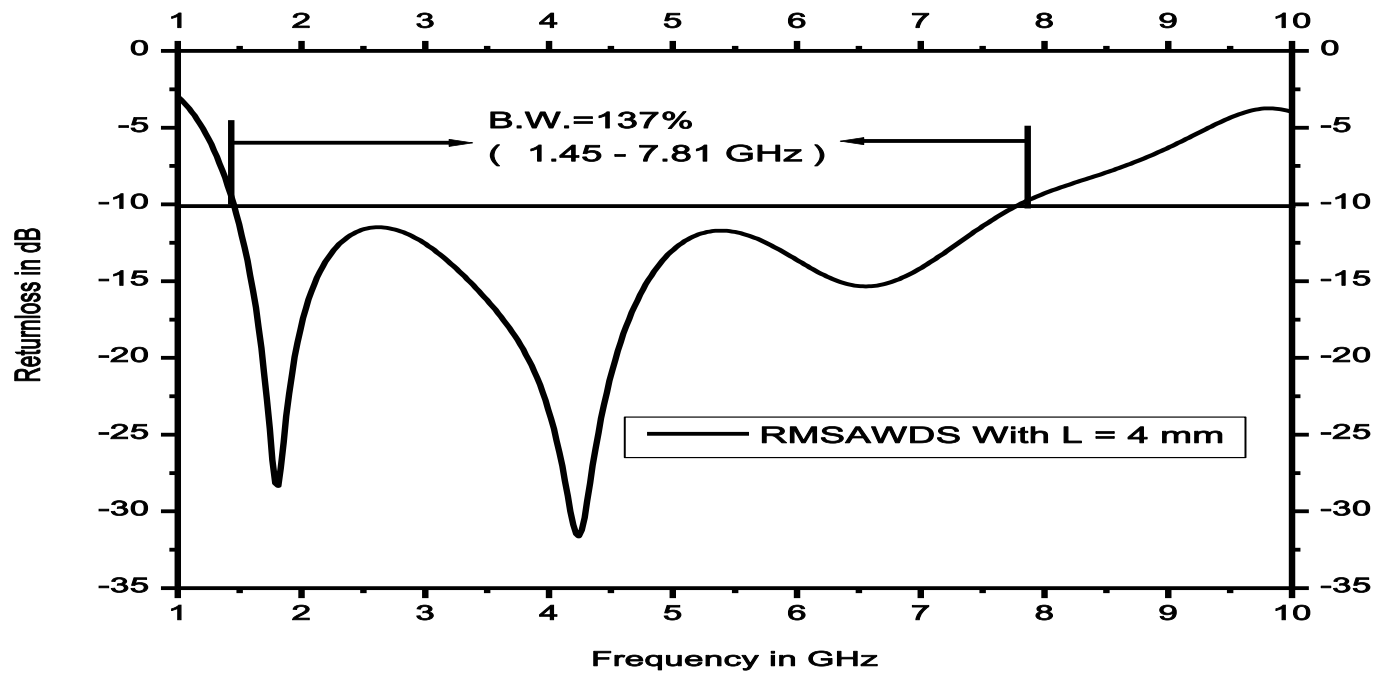

Fig. 8 Variation of return loss versus frequency of RMSAWDS when $\mathrm{L}=4 \mathrm{~mm}$

When length of the stubs are kept at $8 \mathrm{~mm}$ in RMSAWDS the antenna resonates for two bands of frequencies B.W.1 and B.W.2 which are $51 \%(1.40-2.37 \mathrm{GHz})$ and $72.22 \%(3-6.44 \mathrm{GHz})$ respectively as shown in Fig.9. Further it is seen from the figure that, the notch band lies from 2.37 to $3.02 \mathrm{GHz}$ which is shifting towards lower side of frequency spectrum when compared to notch band of Fig. 7. Therefore the variation of size of stubs is effective in controlling the operating band of the antenna.

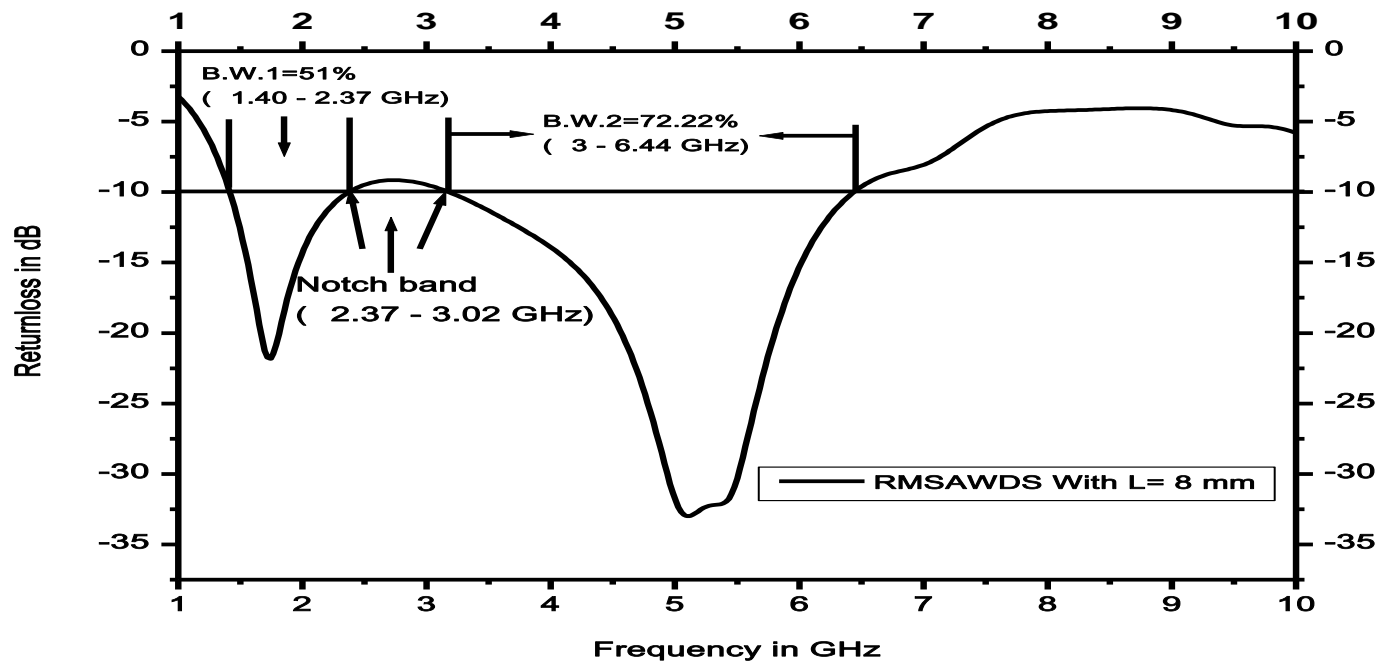

Fig. 9 Variation of return loss versus frequency of RMSAWDS when $\mathrm{L}=8 \mathrm{~mm}$

The surface current distributions across the antenna without and with stubs were also studied. Figure 10 shows the simulated surface current distribution of RMSAWOS measured at resonance frequency 3.02 GHz. The current distribution is dominant at the lower edge of the radiating patch. 


\title{
International Journal of Advanced Research in Electrical, Electronics and Instrumentation Engineering
}

\author{
(An ISO 3297: 2007 Certified Organization)
}

\section{Vol. 4, Issue 3, March 2015}

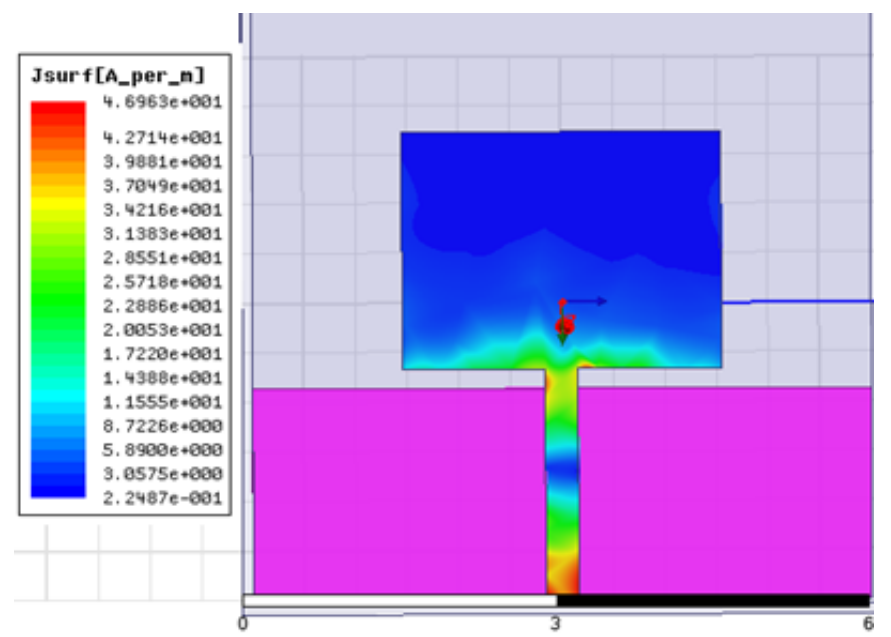

Fig. 10 Surface current distribution of RMSAWOS measured at $3.02 \mathrm{GHz}$

Figure 11 (a) and (b) shows the surface current distribution ofFig.2(a) and Fig. 2(b) respectively for L=2 mm measured at $3.08 \mathrm{GHz}$ and $3.29 \mathrm{GHz}$. The inclusion of stubs at the two corners of the patch the current distribution shifts towards the centre of the radiating patch.

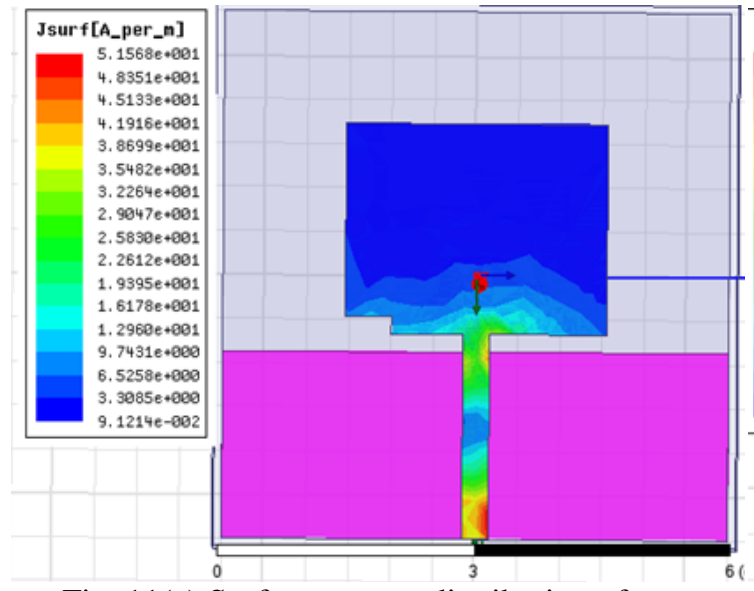

Fig. 11(a) Surface current distribution of RMSAWS1 measured at $3.08 \mathrm{GHz}$

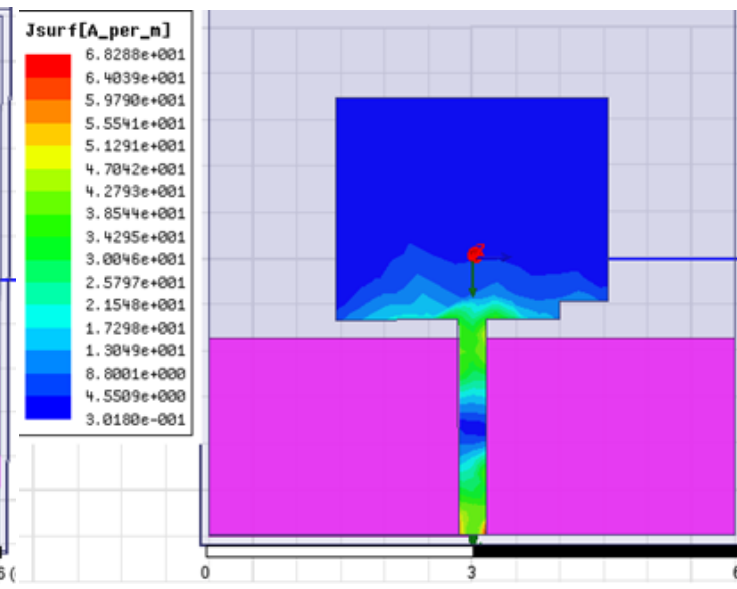

Fig. 11(b)Surface current distribution of RMSAWS2 atmeasure at $3.08 \mathrm{GHz}$

Figure 12 (a), (b) and (c) shows the surface current distribution of RMSAWDS for L=4 mm measures at $1.78 \mathrm{GHz}$, $4.24 \mathrm{GHz}$ and $6.60 \mathrm{GHz}$ respectively. It is seen in Fig. 12 (b) that the current distribution is accumulated at the nonresonating edges of the patch. This gives the flexibility to use the stubs at these edges. Furthermore poor current distribution is observed in Fig. 12(a) and non- resonating edges in Fig. 12 (c). 


\section{International Journal of Advanced Research in Electrical, Electronics and Instrumentation Engineering}

(An ISO 3297: 2007 Certified Organization)

\section{Vol. 4, Issue 3, March 2015}

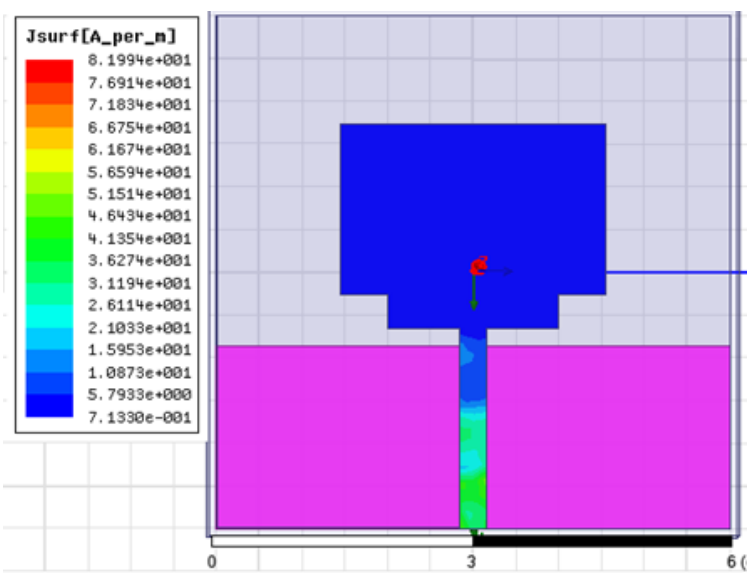

(a) Measured at $1.78 \mathrm{GHz}$

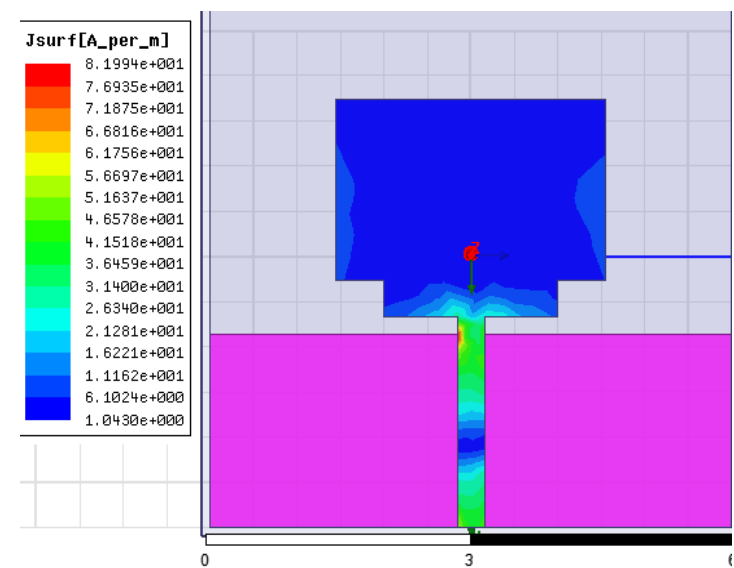

(b) Measuredat $4.24 \mathrm{GHz}$

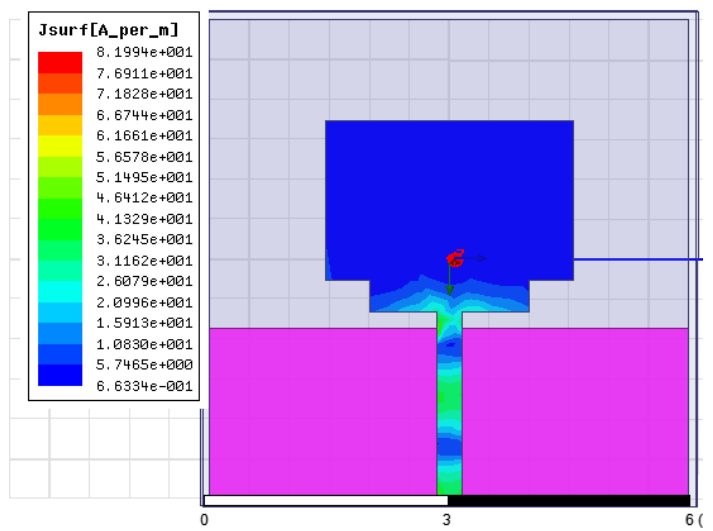

(c) Measuredat $6.60 \mathrm{GHz}$

Fig. 12 Surface current distribution of RMSAWDS, when L= $4 \mathrm{~mm}$

Radiation patterns of RMSAWOS, RMSAWS1.RMSAWS2 and RMSAWDS measured at resonance frequencies are shown in Fig. 13 to 16. From figures it is clear that the proposed antennas shows nearly unidirectional radiation patterns and are similar at resonance frequencies. 


\section{International Journal of Advanced Research in Electrical,} Electronics and Instrumentation Engineering

(An ISO 3297: 2007 Certified Organization)

\section{Vol. 4, Issue 3, March 2015}

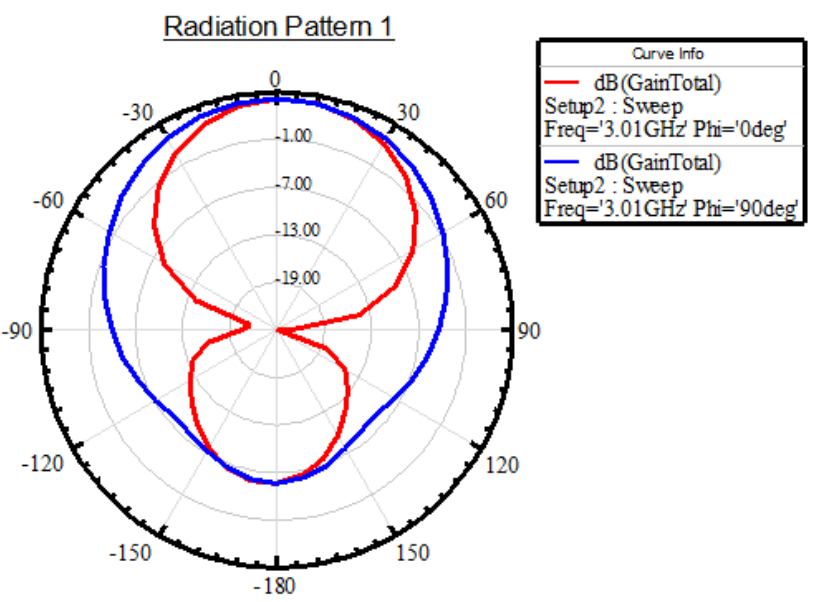

Fig. 13 Typical radiation pattern of RMSAWOS measured at $3.01 \mathrm{GHz}$
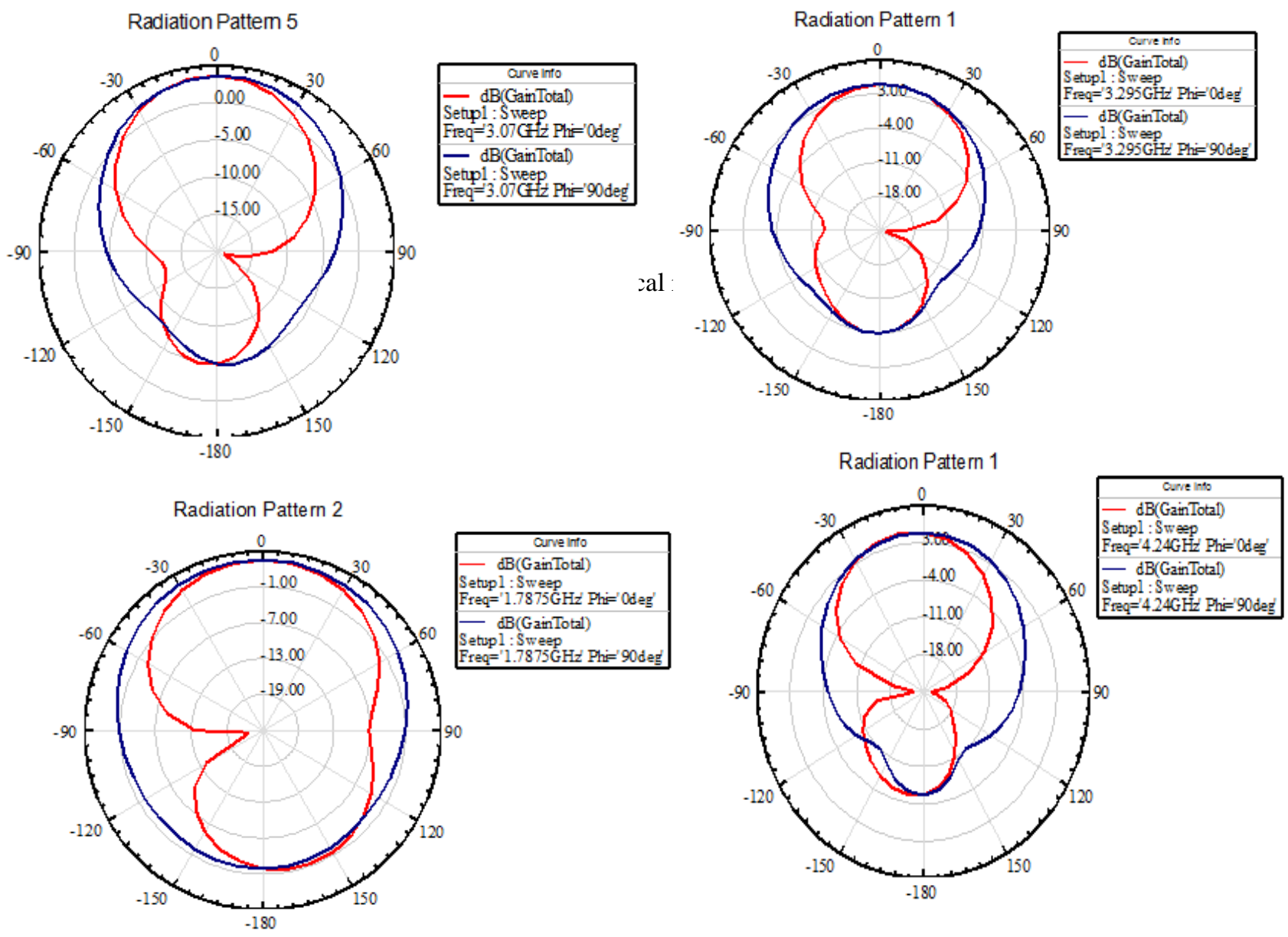

(a) Measured at $1.78 \mathrm{GHz}$

(b) Measured at $4.24 \mathrm{GHz}$ 


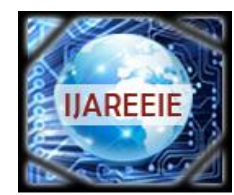

ISSN (Print) : $2320-3765$

ISSN (Online): 2278 - 8875

\section{International Journal of Advanced Research in Electrical, Electronics and Instrumentation Engineering}

(An ISO 3297: 2007 Certified Organization)

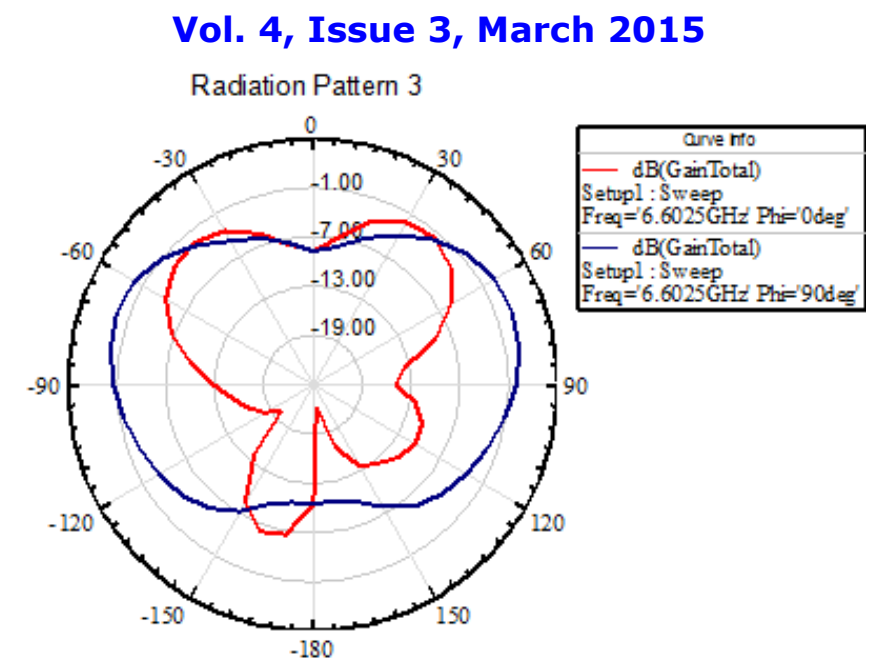

(c)Measured at $6.06 \mathrm{GHz}$

Fig.16 Typical radiation pattern of RMSAWDS for $\mathrm{L}=4 \mathrm{~mm}$

\section{IV.CONCLUSION}

From the detailed study it is found that, the dual band operation of rectangular microstrip antenna with partial ground plane can be converted into triple bands by placing single stub along the width of the patch on the right side of the microstripline with an enhanced bandwidth from $95 \%$ to $115 \%$. The dual bands are merged into a single band and gives highest impedance bandwidth of $137 \%$ by placing two stubs simultaneously along the width of the patch.The proposed antenna also shows the notch band characteristics at higher and lower side of the frequency spectrum. The dual and triple band does not affect much the nature of the radiation characteristics. The antennas are simple in their structure and cost effective because of using low cost glass epoxy substrate material. The frequencies of operating bands of the proposed antennas covers the frequency ranges used for WiMAX, WLAN, Bluetooth, IEEE 802.11a applications.

\section{REFERENCES}

[1] Qing-Xin Chu and Liang-Hua Ye, "Design of compact dual-wideband antenna with assembled monopoles," IEEE Trans. Antennas Propag., vol. 58, no. 12, pp. 4063-4066, Apr. 2004.

[2] Eldek, A. A., A. Z. Elsherbeni, and C. E. Smith, "Square slot antenna for dual wideband wireless communication systems," Journal of Electromagnetic Waves and Applications, Vol. 19, No. 12, 1571-1581, 2005.

[3] Zaker, R., C. Ghobadi, and J. Nourinia, "A modified microstrip fed two-step tapered monopole antenna for UWB and WLAN applications," Progress In Electromagnetics Research, Vol. 77, pp. 137-148, 2007.

[4] Y. D. Dong, W. Hong, Z. Q. Kuai and J. X. Chen, "Analysis of planar ultra wide band antennas with on-ground slot band-notched structures," Antennas and Propagation, IEEE Transactions on, vol. 57, pp. 1886-1893, 2009.

[5] M. Zhang, Y. Z. Yin, J. Ma, Y. Wang, W. C. Xiao and X. J. Liu, "A racket-shaped slot UWB antenna coupled with parasitic strips for bandnotched application," Progress In Electromagnetics Research Letters, vol. 16, pp. 35-44, 2010.

[6] G. P. Gao, Z. L. Mei and B. N. Li, "Novel circular slot UWB antenna with dual band-notched characteristic," Progress In Electromagnetics Research C, vol. 15, pp. 49-63, 2010.

[7] Y. C. Lin and K. J. Hung, "Compact ultra wideband rectangular aperture antenna and band-notched designs," Antennas and Propagation, IEEE Transactions on, vol. 54, pp. 3075-3081, 2006.

[8] Misran N., Islam M. T., Shakib M. N. and Yatim B. "Design of broadband multi-Slotted microstrip patch antenna for wireless system." International Conference of Recent Advances in Microwave Theory and Applications, MICROWAVE 2008, pp 23-25.

[9] Mobashsher A. T., Islam M. T. and Misran N. "Loaded annular ring slot microstrip antenna for wideband and multi-band operation." Microwave Journal, 54(9), pp 146-158.

[10] Pan C.-Y., Horng T.-S., Chen W.-S. and Huang C.-H., "Dual wideband printed monopole antenna for WLAN/WiMAX applications." Antennas and Wireless Propagation Letters, IEEE. 6,pp 149-151.

[11] Sunil Kumar Rajgopal and Satish Kumar Sharma, Senior Member, IEEE "Investigation on UWB Pentagon Shape Microstrip Slot Antenna for Wirelss Communications," IEEE Transactions On Antenna And Propagation, Vol. 57, No.5, May 2009.

[12] K. Chyng, J. Kim, and J. Choi, "Wideband Microstrip-Fed Monopole Antenna Having Frequency Band-Notch Function," IEEE Microwave and Wireless Components Lett., vol.15, no. 11, pp. 766- 768, Nov. 2005.

[13] X. Guo, K. M. Luk, K. F. Lee, Y. L. Chow, "Double u-slot rectangular patch antenna," Electronics Lett., vol. 34, pp. 1805-1806, Sep. 1998.

[14] K. F. Lee, S. Yang, A. A. Kishk, "Dual and multiband u-slot patch antennas", IEEE Antennas Wireless Propagation Lett., vol. 7, pp. 645 -647, Dec. 2008 


\title{
2 \\ ISSN (Print) : $2320-3765$ \\ ISSN (Online): 2278 - 8875 \\ International Journal of Advanced Research in Electrical, Electronics and Instrumentation Engineering
}

\author{
(An ISO 3297: 2007 Certified Organization)
}

\section{Vol. 4, Issue 3, March 2015}

[15] Zhi Ning Chen, Senior Member IEEE \& Terence S. P See and Xianming Qing "Small printed UWB Antenna with reduced Ground Plane effect" IEEE transactions on Antenna \& Propagation Vol. 55 No. 2, February 2007.

[16] T. Yuan, C.-W. Qiu, L.-W. Li, M.S. Leong, and Q. Zhang, "Elliptically shaped ultrawideband patch antenna with band-notch features," Microwave \& Optical Technology Letters, Vol. 50, 2008, pp. 736-738.

[17] Amin M. Abbosh, "Miniaturized Microstrip-Fed Tapered-Slot Antenna with Ultrawideband Performance," IEEE Antennas \& Wireless Propagation Letters, Vol. 8, 2009, pp. 690-692.

\section{BIOGRAPHY}

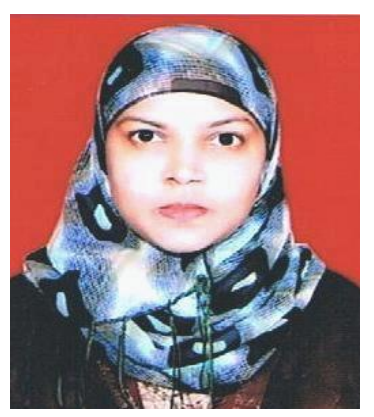

Syeda Rafath Ara has pursued her Master's degree and Master of Philosophy degree in Applied Electronics from Gulbarga University, Gulbarga in the year 1994 and 1997. Currently she is working as an Assistant Professor in the Department of Electronics, Govt. First grade College, Gulbarga, Karnataka State, India. Her area of research includes Microwave electronics. She is pursuing Ph.D. in Applied Electronics under the guidance of Dr. S.N. Mulgi, Professor of Applied Electronics, Gulbarga University, Gulbarga

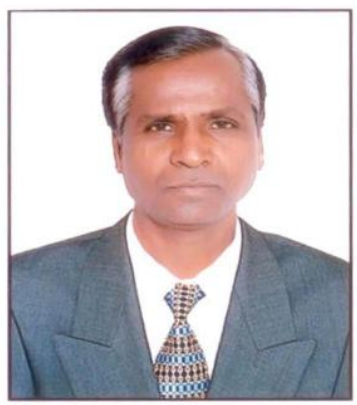

Dr. S. N. Mulgi received his M.Sc., M.Phil. and Ph.D. degree in Applied Electronics fromDepartment of Applied Electronics, Gulbarga University Gulbarga in the year 1986, 1989 and 2004 respectively. He is working as a Professor in Department of P. G. studies and Research in Applied Electronics, Gulbarga University, Gulbarga. He is an active researcher in the field of Microwave Electronics. 